\title{
Influence of Monomer Connectivity, Network Flexibility, and Hydrophobicity on the Hydrothermal Stability of Organosilicas
}

\author{
A. Petra Dral, ${ }^{\dagger}$ Caroline Lievens, ${ }^{\dagger}$ and Johan E. ten Elshof* ${ }^{\dagger}+$ (i) \\ ${ }^{\dagger}$ MESA+ Institute for Nanotechnology, University of Twente, P.O. Box 217, 7500 AE Enschede, The Netherlands \\ ${ }^{\ddagger}$ Faculty of Geo-Information Science and Earth Observation, University of Twente, P.O. Box 217, 7500 AE Enschede, The \\ Netherlands
}

Supporting Information

\begin{abstract}
It is generally assumed that the hydrothermal stability of organically modified silica networks is promoted by high monomer connectivity, network flexibility, and the presence of hydrophobic groups in the network. In this study a range of organosilica compositions is synthesized to explore the extent to which these factors play a role in the hydrothermal dissolution of these materials. Compositions were synthesized from hexafunctional organically bridged silsesquioxanes $\left(\mathrm{OR}_{1}\right)_{3} \mathrm{Si}-\mathrm{R}-\mathrm{Si}\left(\mathrm{OR}_{1}\right)_{3}$ $\left(\mathrm{R}=-\mathrm{CH}_{2}-,-\mathrm{C}_{2} \mathrm{H}_{4}-,-\mathrm{C}_{6} \mathrm{H}_{12}-,-\mathrm{C}_{8} \mathrm{H}_{16}-,-p-\mathrm{C}_{6} \mathrm{H}_{4}-; \mathrm{R}_{1}=-\mathrm{CH}_{3},-\right.$ $\left.\mathrm{C}_{2} \mathrm{H}_{5}\right)$, tetrafunctional $(\mathrm{OEt})_{2} \mathrm{Si}\left(\mathrm{CH}_{3}\right)-\mathrm{C}_{2} \mathrm{H}_{4}-\mathrm{Si}\left(\mathrm{CH}_{3}\right)(\mathrm{OEt})_{2}$ and $\mathrm{Si}(\mathrm{OEt})_{4}$, trifunctional silsesquioxanes $\mathrm{R}^{\prime}-\mathrm{Si}(\mathrm{OMe})_{3}\left(\mathrm{R}^{\prime}=\mathrm{CH}_{3}, n-\mathrm{C}_{3} \mathrm{H}_{7}\right.$, cyclo- $\mathrm{C}_{6} \mathrm{H}_{11}$, phenyl), and bifunctional $\mathrm{Si}\left(i-\mathrm{C}_{3} \mathrm{H}_{7}\right)_{2}(\mathrm{OMe})_{2}$. The bond strain, connectivity and hydroxyl concentration of all networks were estimated using ${ }^{29} \mathrm{Si}$ cross-

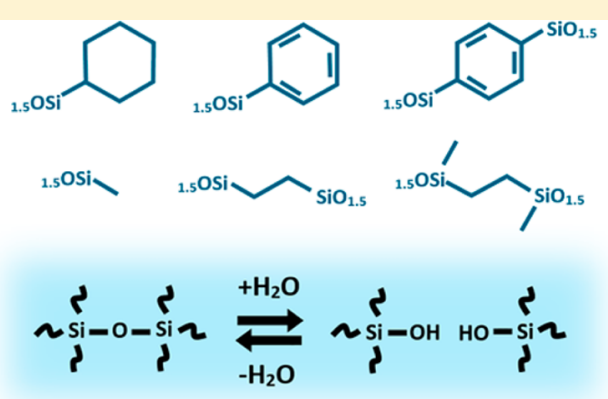
polarized magic angle spinning nuclear magnetic resonance and Fourier-transform infrared spectroscopy. The hydrophilicity was characterized by monitoring the water uptake of the materials in moisture treatments with thermogravimetric analysis, differential scanning calorimetry, and Fourier-transform infrared spectroscopy. The resistance of each network against hydrothermal dissolution in a water/1,5-pentanediol mixture at $80{ }^{\circ} \mathrm{C}$ and $\mathrm{pH} \mathrm{1,7}$, and 13 was analyzed with inductively coupled plasma optical emission spectroscopy and X-ray fluorescence. Bond strain appears to significantly increase the tendency to dissolve under hydrothermal conditions. The stabilizing influences of increased connectivity and hydrophobicity were found to be weak.
\end{abstract}

\section{INTRODUCTION}

The mixed organic-inorganic nature of organosilica materials, glasses in which part of the $\mathrm{Si}-\mathrm{O}-\mathrm{Si}$ linkages are replaced by $\mathrm{Si}-\mathrm{R}$ or $\mathrm{Si}-\mathrm{R}-\mathrm{Si}$ linkages, provides an interesting combination of material properties. The silica moieties provide mechanical rigidity and high thermal and chemical stability, while the organic groups can introduce, e.g., flexibility, hydrophobicity, and a variety of functional groups. The effect of the organic moieties strongly depends on the molecular arrangement of the network. Organic groups in terminal positions $(\mathrm{Si}-\mathrm{R})$ reduce the network connectivity and tend to stick out at the (internal and external) surface. This results in denser packing, easy access to functional groups, and strong surface hydrophobicity. ${ }^{1-3}$ Organic groups in bridging positions $(\mathrm{Si}-\mathrm{R}-\mathrm{Si})$ are part of the network backbone and are more encapsulated by the surrounding siloxane bonds, affecting the micropore structure by acting as spacers. ${ }^{4-7}$ An important advantage of bridged organosilicas is their superior hydrothermal stability as compared to terminal methylated silica and inorganic silica (amorphous $\left.\mathrm{SiO}_{2}\right) .^{8-10}$ Stability under hydrothermal conditions is relevant for various applications, including liquid and gas separation membranes and catalyst supports. Though a variety of factors have been identified that contributes to the hydrothermal stability, the molecular origin is not fully understood.
Reports on the hydrothermal stability of bridged organosilica materials use a variety of definitions and analysis methods. In the area of microporous membranes for molecular separation of gases and liquids (micropores have a pore diameter $<2 \mathrm{~nm}$ according to the IUPAC definition), hydrothermal stability is defined in terms of stable separation performance under hydrothermal conditions. The incorporation of organic bridges between $\mathrm{Si}$ atoms leads to massive improvement of this micropore stability as compared to methylated or inorganic silica, as first reported in $2008,{ }^{8-10}$ and enables stable separation performance under hydrothermal conditions for years. ${ }^{9}$ The increased hydrothermal stability has been reported for microporous organosilica membranes with methylene ${ }^{11,12}$ and ethylene $\mathrm{e}^{8-10,12-16}$ bridges and is assumed to hold for a wide variety of other organically bridged systems as well, though a very small amount of material dissolution is still observed occasionally. ${ }^{16}$ Recently, doping of ethylene-bridged membranes with $\mathrm{Zr}$ has been suggested to further increase the hydrothermal stability, though without demonstrating the improvement compared to the undoped ethylene-bridged network. ${ }^{17}$ In another recent report doping with nm-sized Pd

Received: March 21, 2017

Revised: $\quad$ May 6, 2017

Published: May 17, 2017 


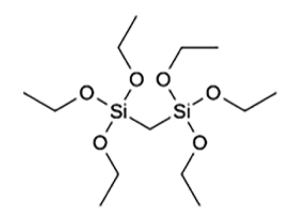

bis(triethoxysilyl)methane (BTESM)

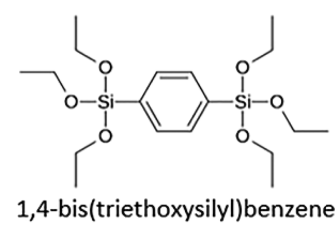
(BTESB)

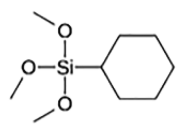

cyclohexyltrimethoxysilane (CHTMS)

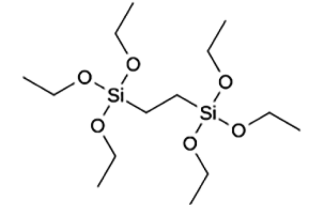

1,2-bis(triethoxysilyl)ethane (BTESE)

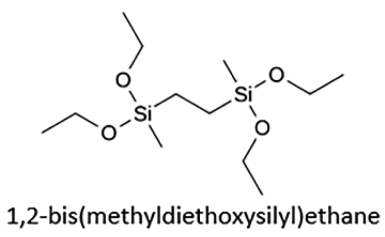
(BMDESE)

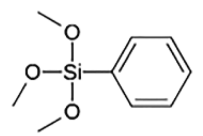

phenyltrimethoxysilane (PHTMS)

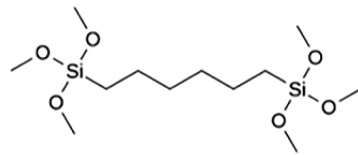

1,6-bis(trimethoxysilyl)hexane (BTMSH)

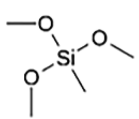

methyltrimethoxysilane (MTMS)

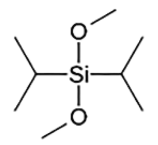

diisopropyldimethoxysilane (DPDMS)

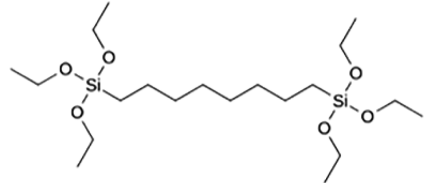

1,8-bis(triethoxysilyl)octane (BTESO)

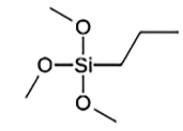

n-propyltrimethoxysilane (PTMS)

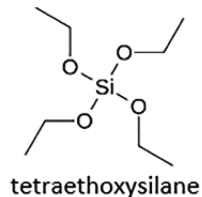

(TEOS)

Figure 1. Chemical structures and abbreviations of the used (organo)silica precursors.

particles was claimed to further improve the hydrothermal stability of ethylene-bridged membranes by limiting the migration of monomeric moieties, ${ }^{18}$ under the assumption that $\mathrm{O}_{1.5} \mathrm{Si}-\mathrm{R}-\mathrm{SiO}_{1.5}$ moieties migrate in a similar way as $\mathrm{SiO}_{2}$ moieties do in silica matrices and thereby ignoring the large differences in monomer size, mass, and connectivity. The observed effects on membrane flux and selectivity were not established to be of hydrothermal origin.

In the field of periodic mesoporous organosilica (PMO) structures, hydrothermal stability is considered on a somewhat larger length scale, focusing on the structural integrity of the ordered mesopores. Stability is generally evaluated by boiling PMO networks in water or exposing them to steam above 100 ${ }^{\circ} \mathrm{C}$ for up to several days and monitoring the mesostructural order by X-ray diffraction. Where the performance of microporous membranes can already be affected by subtle structural evolution without compromising the structural integrity, collapse of mesoporous structures usually requires extensive material dissolution. The stabilizing effect of organic bridges in the context of mesoporous structures has been reported from $1999^{19}$ and includes methylene-bridged, ${ }^{20}$ ethylene-bridged, ${ }^{19-25}$ ethenylene-bridged, ${ }^{23,26}$ phenylenebridged $^{20,24,25,27}$ and biphenylene-bridged ${ }^{24}$ PMO structures. However, partial or complete degradation of these mesostructures has also been reported. ${ }^{19,24,28-31}$

The introduction of organic bridges between $\mathrm{Si}$ atoms clearly reduces the net effect of water on the overall network to an impressive extent compared to inorganic silica and silica with organic terminal groups. However, the majority of the network backbone still consists of siloxane bonds that are by nature susceptible to rehydrolysis. Some level of bond breakage and reformation is to be expected and can lead to significant evolution of the microstructure on long time scales. For example, the long-term stable separation performance of microporous organosilica membranes under hydrothermal conditions is generally accompanied by a subtle change in the flux. ${ }^{8,10,12}$ A detailed study on this phenomenon has been published by us recently, ${ }^{32}$ showing that structural (micropore) evolution can be linked to ongoing chemical condensation. On the other hand, intentional water-induced network rearrangements (termed "hydrothermal restructuring" or "steam firing") are widely used to tune the properties of inorganic silica networks. ${ }^{33-38}$ In organically bridged silica hydrothermal restructuring has been reported to, e.g., increase the condensation degree ${ }^{22}$ and improve the microstructural order. $^{20}$ Other forms of restructuring, either with or without elevated temperatures, involve post-synthesis catalyst treatments such as liquid-phase $\mathrm{NH}_{3}$ or $\mathrm{HCl}$ treatment of mesoporous inorganic silica structures ${ }^{39-41}$ and vapor-phase $\mathrm{HCl}$ or $\mathrm{NH}_{3}$ treatment of microporous ethylene-bridged membranes. ${ }^{42-44}$ It is important to realize that hydrolysis and condensation reactions have a destructive as well as a facilitating function in the structural organization of silicabased networks. This complicated hydrothermal reality involves interconnected and counteracting effects occurring on various length and time scales.

A variety of factors that suppress structural degradation under hydrothermal conditions has been put forward in the literature. Hydrophobicity or nonpolarity introduced by organic groups is suggested to have a stabilizing effect via partial shielding of the siloxane bonds from water molecules. ${ }^{8,13,22,29}$ However, the role of hydrophobic stabilization tends to be overestimated, since many organosilica materials that are classified as hydrothermally stable (especially those with short or rigid organic bridges) have a clear affinity for water., $23,45-47$ Immersion calorimetry data indicate similar surface hydrophilicities for mesoporous ethylene-bridged, phenylene-bridged, and inorganic silica materials. ${ }^{25}$ A more elaborate discussion on the influence of hydrophobic organic segments is given in our recent review on sol-gel processed organosilica membranes. ${ }^{48}$

A suggested stabilizing factor that specifically holds for networks with the organic groups in bridging configuration is the increased theoretical connectivity of a monomer with the surrounding network from 4-fold for conventional $\mathrm{Si}(\mathrm{OR})_{4}$ monomers to 6-fold for organically bridged silica monomers. ${ }^{8,10}$ The chance that all $\mathrm{Si}-\mathrm{O}$ bonds of a monomer unit are hydrolyzed and the monomer disconnects from the network decreases with increasing connectivity. Switching from terminal 
to bridging organic groups in microporous membranes while keeping the total carbon concentration constant indeed yields a significant improvement of the long-term separation performance under hydrothermal conditions, ${ }^{8}$ despite the accompanying increase in microporosity and surface hydrophilicity.

Another suggested stabilizing factor that specifically holds for organically bridged silica is the structural flexibility of the network leading to relaxation of strained siloxane bonds, thereby making them less susceptible to hydrolysis. ${ }^{8,9}$ The Si$\mathrm{O}-\mathrm{Si}$ angle can vary roughly between 134 and $180 \mathrm{deg}{ }^{49}$ and though this allows a wide range of network configurations without compromising structural integrity, not all bonds are in the lowest energy state. Additional rotational freedom and empty space introduced by organic bridges can help relieve the strain on the siloxane bonds and increase their resistance against hydrolysis. Terminal organic groups leave even more rotational freedom to the network, but they generally do not act as spacers and yield a denser packing of the network that sterically hinders reorganization after solidification. Bond relaxation may also be the underlying factor in stabilization trends known from inorganic silica, where silica dissolution can be suppressed by introducing crystallinity ${ }^{50}$ or increasing the condensation degree. ${ }^{51,52}$ Crystalline networks are expected to have more optimal bond configurations than amorphous systems. An increasing condensation degree as such does not necessarily increase bond relaxation, but post-treatments aiming at a higher condensation degree induce structural rearrangements on a larger scale as well, including network relaxation. Though all these factors have been proposed as origins for hydrothermal stability, their effects have not been studied systematically.

This paper presents a systematic study on the influence of monomer connectivity, network flexibility, and water uptake on the hydrothermal dissolution of a series of organosilica materials prepared via sol-gel synthesis. Materials were prepared from the precursors listed in Figure 1. The bond strain, connectivity, and hydroxyl concentration of each network were estimated with ${ }^{29} \mathrm{Si}$ cross-polarized magic angle spinning nuclear magnetic resonance $\left({ }^{29} \mathrm{Si}\right.$ CP-MAS NMR) and Fourier-transform infrared spectroscopy (FTIR). The water uptake was analyzed with moisture treatments with thermogravimetric analysis and differential scanning calorimetry (TGA-DSC) and FTIR monitoring. The resistance against hydrothermal dissolution was tested at $\mathrm{pH} \mathrm{1,} \mathrm{7,} \mathrm{and} 13$ with inductively coupled plasma optical emission spectroscopy (ICP-OES) and X-ray fluorescence (XRF) analyses. All in all, a strong correlation between bond strain and hydrothermal dissolution is presented and the stabilizing effect of increased connectivity and hydrophobicity is shown to be weak. Routes to further stability improvement are proposed.

\section{EXPERIMENTAL SECTION}

Chemicals. Bis(triethoxysilyl)methane (97\% purity), 1,2-bis(triethoxysilyl)ethane (97\% purity), 1,6-bis(trimethoxysilyl)hexane (97\% purity), 1,8-bis(triethoxysilyl)octane (97\% purity), 1,4-bis(triethoxysilyl)benzene (95\% purity), 1,2-bis(methyldiethoxysilyl)ethane (purity unknown), methyltrimethoxysilane (97\% purity), $n$ propyltrimethoxysilane (98\% purity), cyclohexyltrimethoxysilane (97\% purity), phenyltrimethoxysilane (97\% purity), diisopropyldimethoxysilane (95\% purity), and tetraethoxysilane (99\% purity) were obtained from ABCR. Nitric acid was obtained from Sigma-Aldrich (70 wt \% aqueous solution) and Acros (65 wt \% aqueous solution). Ethanol (dehydrated, $99.99 \%$ purity) was obtained from VWR and SeccoSolv. Sodium hydroxide ( $98.5 \%$ purity) was obtained from
Sigma-Aldrich. 1,5-Pentanediol (98\% purity) was obtained from Acros. Certipur silicon ICP standard (1000 $\left.\mathrm{mg} \mathrm{L}^{-1} \mathrm{Si}, 2 \% \mathrm{NaOH}\right)$ was obtained from Merck.

Sample Preparation. (Organo)silica materials were synthesized by adding demineralized water and aqueous $\mathrm{HNO}_{3}(65 \mathrm{wt} \%)$ to dry ethanol at room temperature, followed by adding the (organo)silica precursor under stirring. All quantities are listed in Table 1. The

Table 1. Reactant Quantities and Reaction Times for the Synthesis of the (Organo)silica Materials

\begin{tabular}{lccccc} 
& $\begin{array}{c}\text { ethanol } \\
{[\mathrm{mL}]}\end{array}$ & $\begin{array}{c}\text { water } \\
{[\mathrm{mL}]}\end{array}$ & $\begin{array}{c}\mathrm{HNO}_{3} 65 \text { wt } \\
\%[\mathrm{~mL}]\end{array}$ & $\begin{array}{c}\text { precursor } \\
{[\mathrm{mL}]}\end{array}$ & $\begin{array}{c}\text { reaction } \\
\text { time }[\mathrm{min}]\end{array}$ \\
TEOS & 30.0 & 6.06 & 1.492 & 18.76 & 180 \\
BTESM & 29.0 & 3.67 & 0.903 & 11.86 & 180 \\
BTESE & 25.0 & 3.24 & 0.798 & 11.12 & 180 \\
BTMSH & 60.0 & 2.35 & 0.579 & 7.04 & 50 \\
BTESO & 50.0 & 1.59 & 0.390 & 6.95 & 55 \\
BTESB & 30.0 & 1.21 & 0.298 & 4.48 & 50 \\
BMDESE & 27.0 & 2.09 & 0.515 & 9.31 & 180 \\
MTMS & 35.0 & 4.11 & 1.01 & 10.87 & 180 \\
PTMS & 60.0 & 2.38 & 0.585 & 7.73 & 50 \\
CHTMS & 70.0 & 1.57 & 0.387 & 5.95 & 50 \\
PHTMS & 80.0 & 1.78 & 0.439 & 6.17 & 50 \\
DPDMS & 70.0 & 1.04 & 0.255 & 5.80 & 180 \\
\hline
\end{tabular}

mixture was then heated to $60{ }^{\circ} \mathrm{C}$ in an oil bath for the time periods listed in Table 1, cooled to room temperature in a water bath, and poured in Petri dishes to dry. BMDESE- and PTMS-derived materials were dried further in an oven at $140{ }^{\circ} \mathrm{C}$. The resulting samples were used in millimeter-sized pieces for hydrothermal treatment and were ground to powder by ball milling for ${ }^{29} \mathrm{Si}$ CP-MAS NMR, FTIR, and TGA-DSC analyses. Reactant ratios (for all syntheses the $\mathrm{HNO}_{3}$ : $\mathrm{H}_{2} \mathrm{O}$ : alkoxy ratio was 0.064:1.1:1.0) and reaction times were derived from synthesis conditions reported elsewhere, ${ }^{53}$ and precursor concentrations were adjusted to prevent premature gelation. All samples were stored under ambient conditions.

Hydrothermal Treatment. Millimeter-sized sample pieces were consolidated at $300{ }^{\circ} \mathrm{C}$ in $\mathrm{N}_{2}$ for $3 \mathrm{~h}$ (except DPDMS-derived material due to evaporation below $200{ }^{\circ} \mathrm{C}$ ). For every sample a total of 1.0 mmol Si (59-135 mg sample assuming $100 \%$ condensation) was soaked in $10 \mathrm{~mL}$ of demineralized water with $15 \mathrm{vol} \% 1,5$-pentanediol at $\mathrm{pH} 1(0.1 \mathrm{M} \mathrm{HCl}), 7$, and $13(0.1 \mathrm{M} \mathrm{NaOH})$. The mixtures were kept at $80^{\circ} \mathrm{C}$ under stirring for $46 \mathrm{~h}$, subsequently filtered with $0.2 \mu \mathrm{m}$ cellulose filters, and analyzed with ICP-OES and XRF within $8 \mathrm{~h}$.

${ }^{29} \mathrm{Si}$ Nuclear Magnetic Resonance Spectroscopy. ${ }^{29} \mathrm{Si}$ nuclear magnetic resonance spectra of powder samples were obtained with cross-polarization and magic angle spinning on a Bruker Avance 300 system. Spectra were recorded with a contact time of $3 \mathrm{~ms}$ (optimized for BTESE-derived material), a recycle delay of $2 \mathrm{~s}$, and 1000 scans per sample. To estimate the condensation degrees the $\mathrm{Q}, \mathrm{T}$, and $\mathrm{D}$ peaks were smoothened (averaging over 5 data points) and fitted with nearGaussian components. Fitting was based on optimization of the peak location, the full width at half-maximum (asymmetric), the Gaussian/ Lorentzian mix (asymmetric), and the baseline.

Infrared Spectroscopy. Fourier-transform infrared spectra of powder samples were obtained with a Bruker Tensor 27 machine and a room temperature DLaTGS detector. The spectra in Figure 3 were measured in attenuated total reflection mode with a Pike Technologies GladiATR accessory. Spectra were recorded with a resolution of 2 $\mathrm{cm}^{-1}$ and 78 scans per measurement. The spectra in Figure 4 were measured in diffuse reflectance mode with a Harrick Praying Mantis accessory and a high temperature reaction chamber with $\mathrm{ZnSe}$ windows. The reaction chamber was flushed continuously with humidified $\mathrm{N}_{2}$ during the experiments and the gas outlet was located directly underneath the sample with $\mathrm{KBr}$ background, ensuring proper gas flow through the powder. The $\mathrm{N}_{2}$ was humidified to a constant level by bubbling through demineralized water at room temperature. 
The $\mathrm{KBr}$ background was stabilized at $30^{\circ} \mathrm{C}$ for at least $45 \mathrm{~min}$ before recording the background spectrum, after which a small amount of sample powder was put on top, and the atmosphere was stabilized again for at least $45 \mathrm{~min}$. The sample was then heated to $300{ }^{\circ} \mathrm{C}$, kept there for $3 \mathrm{~h}$, cooled to $50{ }^{\circ} \mathrm{C}$, kept there for $3 \mathrm{~h}$, and heated again to $300{ }^{\circ} \mathrm{C}$. Heating and cooling rates were $1{ }^{\circ} \mathrm{C} \mathrm{min}^{-1}$. Spectra were recorded in situ every $10 \mathrm{~min}$ with a resolution of $2 \mathrm{~cm}^{-1}$ and 78 scans per measurement.

Thermogravimetric Analysis and Differential Scanning Calorimetry. Thermogravimetric and differential scanning calorimetry data of powder samples were recorded with a Netzsch STA 449 F3 Jupiter machine and platinum crucibles. The sample was heated to $300{ }^{\circ} \mathrm{C}$ for $3 \mathrm{~h}$, followed by three cycles of cooling to $50{ }^{\circ} \mathrm{C}$ and heating to $300{ }^{\circ} \mathrm{C}$. Heating and cooling rates were $1{ }^{\circ} \mathrm{C} \mathrm{min}^{-1}$, and the sample was kept at each target temperature for $3 \mathrm{~h}$. The sample was

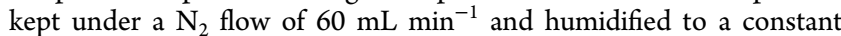
level by bubbling through demineralized water at room temperature. Data were recorded every $15 \mathrm{~s}$.

Inductively Coupled Plasma Optical Emission Spectroscopy. Inductively coupled plasma optical emission spectra of hydrothermal solutions were obtained with a PerkinElmer Optima DV8300 machine with $1.5 \mathrm{~mL} \mathrm{~min}^{-1}$ sample inlet and $0.65 \mathrm{~L} \mathrm{~min}^{-1}$ nebulizer gas flow. $\mathrm{Si}$ concentrations were measured axially ( $\mathrm{Si}$ lines $251.611 \mathrm{~nm}, 212.412$ $\mathrm{nm}, 288.158 \mathrm{~nm}, 252.851 \mathrm{~nm}$ ) and averaged over three replicates. Calibration curves from a $\mathrm{Si}$ standard were obtained for each $\mathrm{pH}$ to exclude matrix effects; a calibration curve at $\mathrm{pH} 7$ was made for the $\mathrm{pH}$ 1 series due to precipitation of the standard at low $\mathrm{pH}$. The hydrothermal solutions were diluted with demineralized water at the corresponding $\mathrm{pH}$ to reduce the 1,5-pentanediol concentration from 15 to 9 vol \% for plasma stability.

X-ray Fluorescence Spectroscopy. X-ray fluorescence spectra of undiluted hydrothermal solutions were obtained with a Bruker S8 Tiger machine equipped with a rhodium tube and measuring at approximately $4 \mathrm{~kW}$.

\section{RESULTS AND DISCUSSION}

Network State and Hydroxyl Concentration. The network state and hydroxyl concentration of the organosilica materials were investigated with ${ }^{29} \mathrm{Si}$ CP-MAS NMR spectroscopy. Spectra of the as-prepared materials are shown in Figure 2. The chemical shifts may have been affected by nonhydrolyzed alkoxy residues, but differences between alkoxy- and hydroxyl-substituted $\mathrm{Si}$ signals are reported to be very small. ${ }^{54}$ When looking at the peak positions of the $\mathrm{T}$ signals, the magnetic shielding of the $\mathrm{Si}$ nucleus increases (decreasing chemical shift) in the order BTESE $<$ BTMSH $\approx$ BTESO $\approx$ MTMS $\approx$ PTMS $<$ BTESM $\approx$ CHTMS $\ll$ PHTMS $<$ BTESB. The almost identical chemical shifts for BTMSH-, BTESO-, MTMS- and PTMS-derived networks correspond with them all having a high network flexibility (the organic bridges are either long and flexible or absent) that enables close-to-optimal network organizations with minimal bond strain. This observation is confirmed by the FTIR spectra in Figure 3, where the $\mathrm{Si}-\mathrm{O}-\mathrm{Si}$ stretching band $\left(1150-1000 \mathrm{~cm}^{-1}\right)^{55,56}$ occurs at a similar low frequency for BTMSH-, BTESO-, and MTMS-derived material (for excluded samples the spectra were too complicated to pinpoint the $\mathrm{Si}-\mathrm{O}-\mathrm{Si}$ stretching band). For BTESE-derived powder, only its $\mathrm{T}^{3}$ signal had a higher chemical shift than in BTMSH-, BTESO-, MTMS-, and PTMS-derived networks. This can be explained with its $\mathrm{T}^{1}$ and $\mathrm{T}^{2}$ centers being in a similar relaxed state and the formation of a third siloxane bond on the same Si atom introducing some bond strain. Increasing bond strain leading to higher chemical shifts (deshielding of the Si nucleus) is reported for cyclic siloxane species. ${ }^{57}$ The BTESM-derived network is expected to be significantly strained, as also indicated by the FTIR $\mathrm{Si}-\mathrm{O}-\mathrm{Si}$

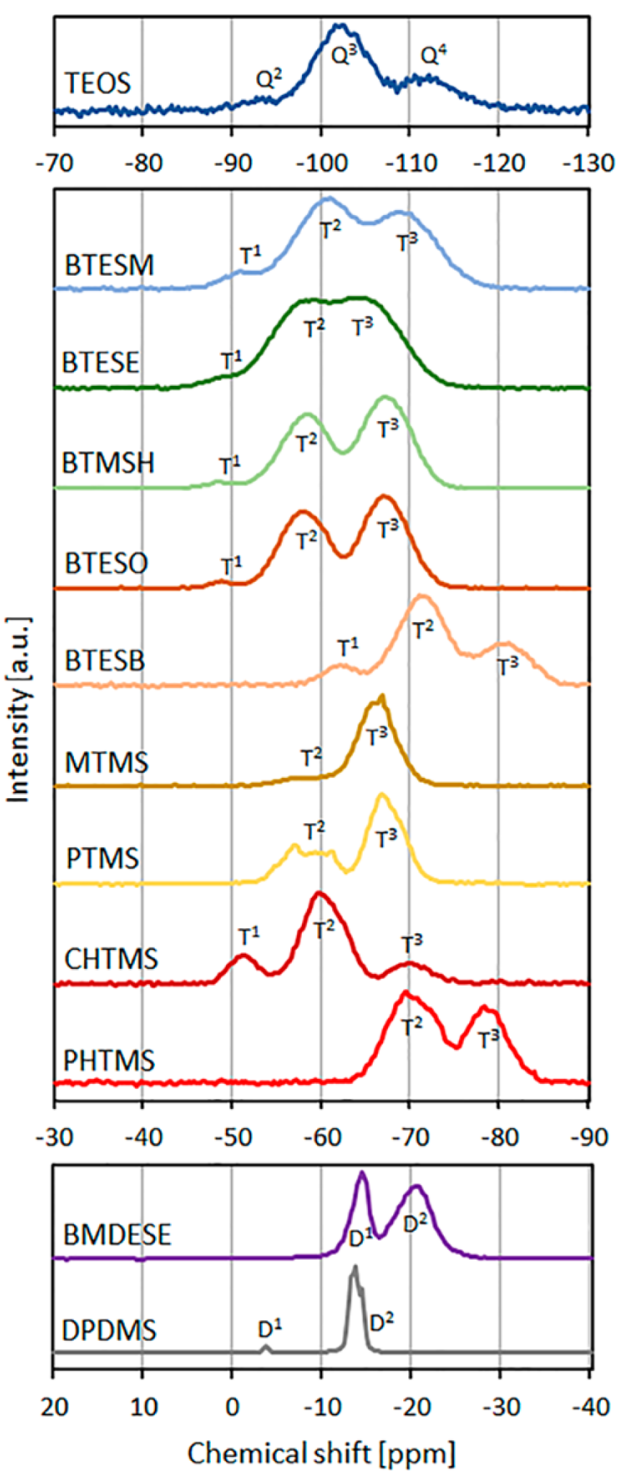

Figure 2. ${ }^{29} \mathrm{Si} \mathrm{CP}-\mathrm{MAS}$ NMR spectra of all (organo)silica materials.

stretching vibration shifting to higher frequency for BTESM-, BTESB-, and TEOS-derived material in Figure 3, but its chemical shift was lower than for the other organically bridged networks. This could be due to the close proximity of surrounding atoms offering increased magnetic shielding of the Si nuclei as a result of the shorter bridges creating smaller micropores. The CHTMS-derived network, also closely packed due to the bulky hexyl rings filling up empty spaces, had a similar high magnetic shielding. The observed lower chemical shift of PHTMS- and BTESB-derived materials as compared to the other $\mathrm{T}$ compounds corresponds with phenyl substitution providing better magnetic shielding of the Si nucleus than alkyl substitution does. ${ }^{58}$ The slightly lower shielding for the PHTMS-derived network as compared to the BTESB-derived network can be explained with increased bond strain due to twice as many bulky phenyl rings that have to be accommodated in the network. The reduced magnetic shielding in DPDMS-derived material as compared to BMDESE-derived material can be explained by increased steric hindrance of the double isopropyl groups yielding more strained siloxane bonds. Bond strain indicated by ${ }^{29} \mathrm{Si}$ CP-MAS NMR is expected to mainly represent $\mathrm{X}-\mathrm{Si}$ stretching or $\mathrm{X}-\mathrm{Si}-\mathrm{X}$ bending; though 


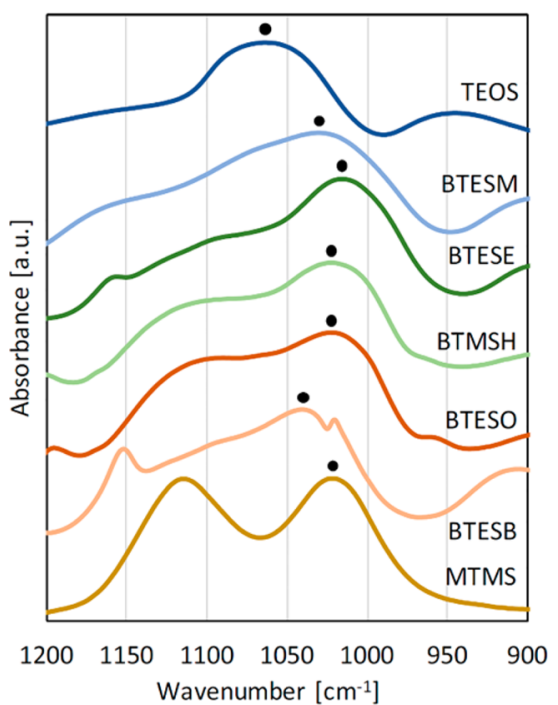

Figure 3. FTIR spectra (attenuated total reflection) of part of the (organo)silica materials. The dots indicate the $\mathrm{Si}-\mathrm{O}-\mathrm{Si}$ stretching vibration.

$\mathrm{Si}-\mathrm{O}-\mathrm{Si}$ bending occurs more readily, this distortion affects the electron density around Si less.

The overall condensation degrees of all materials were estimated from the deconvoluted ${ }^{29} \mathrm{Si}$ CP-MAS NMR spectra and are listed in Table 2 (an overview of all deconvolutions is

Table 2. Condensation Degree, Hydroxyl Concentration and Actual Connectivity of All (Organo)silica Materials as Derived from ${ }^{29} \mathrm{Si}$ CP-MAS NMR Spectra

\begin{tabular}{lccc} 
material & condensation degree [\%] & OH per Si & SiOSi per monomer \\
TEOS & $>80$ & $<0.8$ & $>3.2$ \\
BTESM & 79 & 0.6 & 4.7 \\
BTESE & 82 & 0.5 & 4.9 \\
BTMSH & 85 & 0.5 & 5.1 \\
BTESO & 84 & 0.5 & 5.0 \\
BTESB & 78 & 0.7 & 4.7 \\
MTMS & 98 & 0.1 & 2.9 \\
PTMS & 88 & 0.4 & 2.6 \\
CHTMS & 66 & 1.0 & 2.0 \\
PHTMS & 83 & 0.5 & 2.5 \\
BMDESE & 82 & 0.4 & 3.3 \\
DPDMS & 98 & 0.0 & 2.0 \\
\hline
\end{tabular}

shown in the Supporting Information). The condensation degrees indicate the as-prepared state without thermal consolidation and reflect intrinsic as well as synthesisdependent material properties. From these condensation degrees the hydroxyl concentration and actual connectivity (number of siloxane bonds per monomer) were calculated. CPMAS NMR is not a quantitative technique in principle, because the cross-polarization efficiency and rate depend on the local chemistry. In practice, ${ }^{29} \mathrm{Si}$ CP-MAS NMR results have been shown to offer good quantitative approximations for organosilica materials with arylene and alkylene bridges, ${ }^{46,59}$ and all Ttype $\mathrm{Si}$ nuclei in the present study have neighboring organic protons in the same configuration except for the MTMSderived network. The obtained values and trends are thus expected to be reasonably accurate. $\mathrm{Q}^{4}$-type $\mathrm{Si}$ resonance is known to be hindered by a low cross-polarization efficiency, ${ }^{60}$ yielding an underestimation of the condensation degree and an overestimation of the hydroxyl concentration for TEOS-derived material.

For the networks with flexible organic bridges the condensation degree slightly increased with increasing bridge length, probably due to increased rotational freedom of the monomers. As for steric hindrance, bridges also act as spacers and in this range of relatively short bridges (up to eight $\mathrm{CH}_{2}$ units) the larger micropore size for longer bridges accommodated their larger volume. Networks with terminal organic groups and thus more organizational freedom had somewhat higher condensation degrees than networks with equivalent bridging groups (MTMS vs BTESE, PTMS vs BTMSH). On the other hand, the condensation degree in networks with terminal organic groups significantly decreased for increasingly bulky groups. The high condensation degree of MTMS-derived powder (98\%) suggests a densely packed network in which the methyl group fits well, as also indicated by the ability of methylated silica to crystallize. ${ }^{61,62}$ Interestingly, the addition of terminal methyl groups in BMDESE-derived material as compared to BTESE-derived powder increased the rotational freedom of molecular segments but did not increase the condensation degree. The methyl groups did not preferentially replace noncondensed hydroxyl groups, suggesting that the hydroxyl groups had little freedom to rearrange or that the ethylene bridges introduced too much spacing to enable higher condensation degrees. PHTMS-derived networks had a significantly higher condensation degree than CHTMS-derived networks, which could be due to the rigidity and $\pi-\pi$ stacking tendency of phenyl rings. The average number of hydroxyl groups per $\mathrm{Si}$ atom varied between 0.5 and 0.7 for the organically bridged networks, indicating significant hydrophilicity. For the networks with terminal organic groups the number of hydroxyl groups per $\mathrm{Si}$ atom varied between 0.0 and 1.0, with MTMS- and DPDMS-derived materials being strongly hydrophobic and CHTMS-derived material having a high concentration of hydrophilic sites. The actual connectivity was around 5 for the organically bridged networks and around 2-3 for the networks with terminal organic groups. The materials with the lowest actual connectivity were derived from DPDMS and CHTMS.

Water Uptake. The hydrophilicity of the networks is related to their hydroxyl concentration, listed in Table 2 above. In addition, the water uptake of a network also depends on the presence of microporosity and the accessibility of hydrophilic groups. Microporosity is generally present in TEOS-derived networks as well as networks with rigid phenylene bridges or flexible alkylene bridges up to eight $\mathrm{CH}_{2}$ units (with acidcatalyzed syntheses). ${ }^{53}$ The overall amount of water uptake is an indication of the scale at which hydrolysis may take place. Furthermore, the uptake of water proves close contact between the organosilica matrix and aqueous species and thus can rule out hydrophobicity as main origin of hydrothermal stability. The water uptake of the samples was measured by subjecting them to repeated temperature cycles from 300 to $50{ }^{\circ} \mathrm{C}$ under a humidified $\mathrm{N}_{2}$ flow with in situ TGA-DSC and FTIR monitoring. The results reflect intrinsic as well as synthesisdependent material properties, but variations in synthesis parameters are not expected to affect the qualitative observations discussed here. Results are shown in Figure 4, except for DPDMS-derived material due to its complete evaporation below $200{ }^{\circ} \mathrm{C}$. 

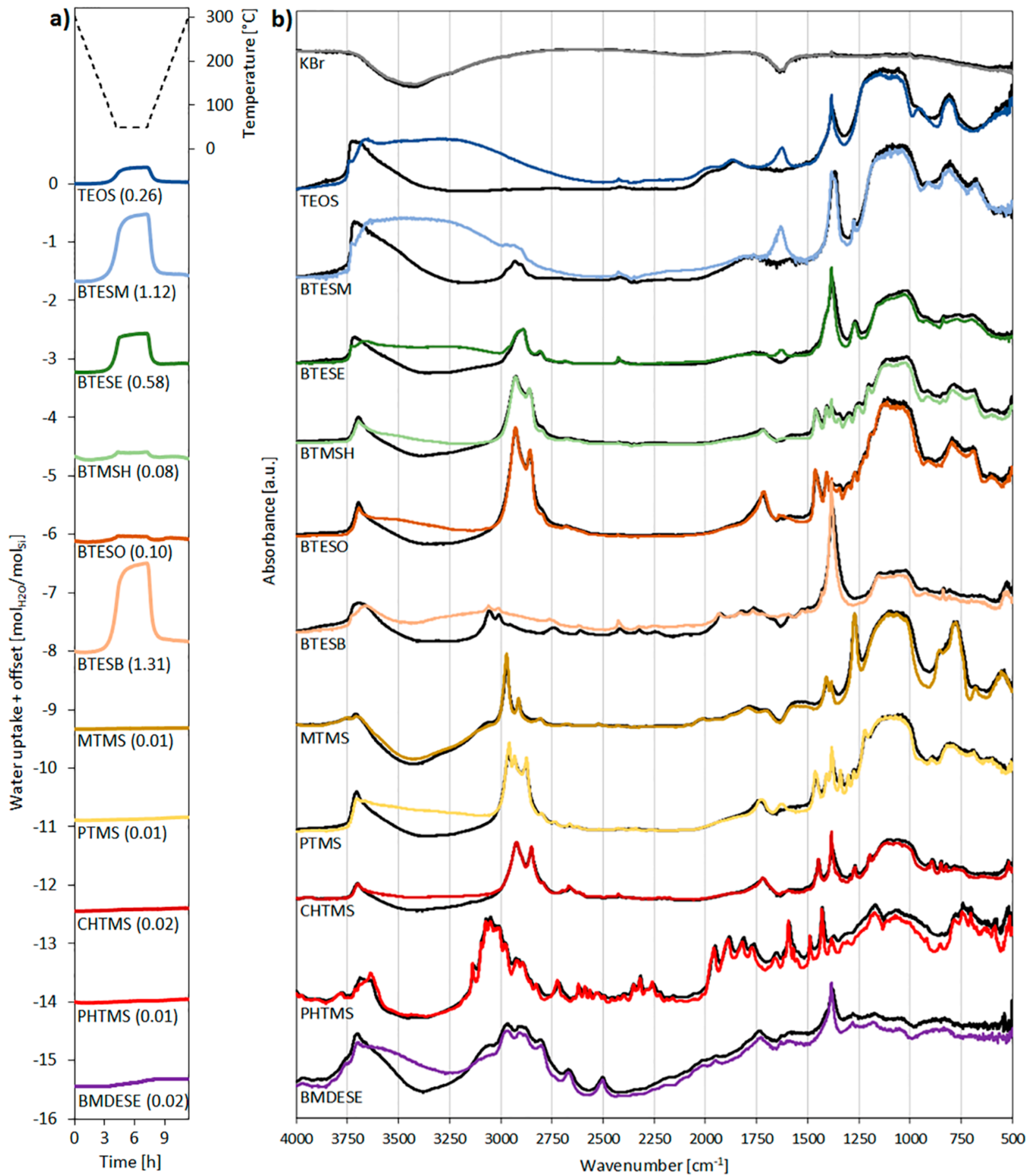

Figure 4. (a) TGA data of all (organo)silica materials under humidified $\mathrm{N}_{2}$ flow. The curves are plotted as water uptake per mol Si atoms, with a vertical offset to facilitate comparison. The listed values denote the uptake at the end of the $50{ }^{\circ} \mathrm{C}$ segment averaged over three consecutive cycles. (b) FTIR spectra (diffuse reflectance) of all (organo)silica materials under humidified $\mathrm{N}_{2}$ flow at the end of the $300{ }^{\circ} \mathrm{C}$ segment (black curves) and at the end of the $50{ }^{\circ} \mathrm{C}$ segment (colored curves).

The TGA curves for TEOS-, BTESM-, BTESE-, and BTESBderived networks show a clear uptake of mass on cooling below $100{ }^{\circ} \mathrm{C}$, and the DSC signals (not shown) indicate an exothermic process, corresponding with physical condensation of water. Their FTIR spectra show increasing $\mathrm{H}-\mathrm{O}-\mathrm{H}$ scissoring vibrations $\left(1611 \mathrm{~cm}^{-1}\right.$ in silica glass $),{ }^{63}$ confirming the uptake of molecular water. Increasing $\mathrm{Si}-\mathrm{O}$ stretching vibrations of silanol groups $\left(\sim 900 \mathrm{~cm}^{-1}\right)^{55,56,63}$ indicate that some siloxane bonds were hydrolyzed. Furthermore, the $\mathrm{O}-\mathrm{H}$ stretching vibrations in hydrogen-bonded hydroxyl groups (3600-3200 $\left.\mathrm{cm}^{-1}\right)^{55,56,63}$ increased, and the $\mathrm{O}-\mathrm{H}$ stretching vibration in isolated silanol groups $\left(\sim 3690 \mathrm{~cm}^{-1}\right)^{55}$ decreased. All this corresponds with networks having significant hydroxyl concentrations and open microporosity. BTMSH- and BTESOderived networks had hydroxyl concentrations similar to those of the other bridged networks, but their relatively long alkylene 


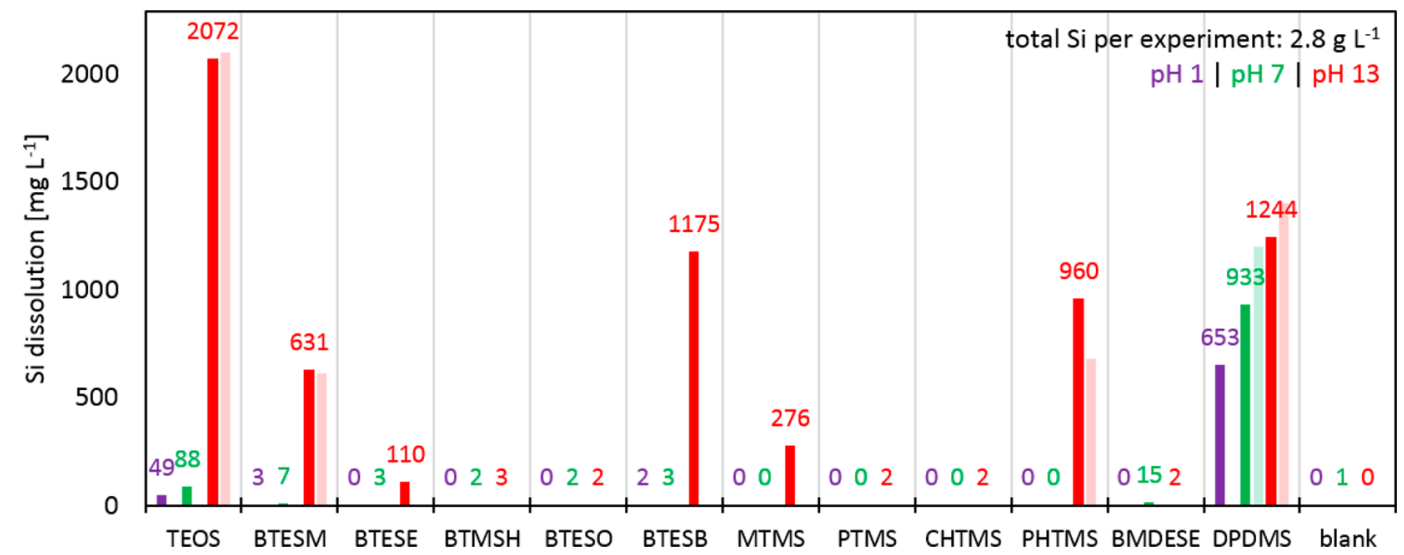

Figure 5. Si concentrations measured in solution after soaking of (organo)silica pieces in demineralized water with 15 vol \% 1,5-pentanediol and varying $\mathrm{pH}$ at $80^{\circ} \mathrm{C}$ for $46 \mathrm{~h}$. The darker colored bars with corresponding numeric values represent ICP-OES data recorded at $252.851 \mathrm{~nm}$ with a detection limit of $0.8 \mathrm{mg} \mathrm{L}^{-1}$ (concentrations below the detection limit are shown as zero) and a relative standard deviation $<3 \%$ for all values. The lighter colored bars represent XRF data with an estimated detection limit of $500 \mathrm{mg} \mathrm{L}{ }^{-1}$.

bridges tend to fill up empty spaces and make the pore surfaces hydrophobic. The TGA curves indeed show only minor mass uptake. Their FTIR spectra indicate a clear increase in $\mathrm{O}-\mathrm{H}$ stretching vibrations in hydrogen-bonded hydroxyl groups (3600-3200 $\left.\mathrm{cm}^{-1}\right)$. Minor increases in the $\mathrm{H}-\mathrm{O}-\mathrm{H}$ scissoring vibrations $\left(1611 \mathrm{~cm}^{-1}\right.$ ) (though barely distinguishable for $\mathrm{BTMSH}$ ) and $\mathrm{Si}-\mathrm{O}$ stretching vibrations in silanol groups $\left(\sim 900 \mathrm{~cm}^{-1}\right)$ indicate the uptake of some molecular water and hydrolysis of siloxane bonds, respectively. The TGA curves indicate no mass uptake for PTMS-, CHTMS-, and BMDESEderived networks, despite their significant hydroxyl concentrations of $0.4,1.0$, and 0.4 hydroxyl groups per $\mathrm{Si}$, respectively. However, the increase of their $\mathrm{O}-\mathrm{H}$ stretching vibrations in hydrogen-bonded hydroxyl groups (3600-3200 $\mathrm{cm}^{-1}$ ) does suggest an increasing hydroxyl concentration and for the PTMS-derived network also the $\mathrm{H}-\mathrm{O}-\mathrm{H}$ scissoring vibrations $\left(1611 \mathrm{~cm}^{-1}\right)$ increased. Apparently, the terminal alkyl groups filled up most of the space in between the network backbones. For MTMS- and PHTMS-derived networks both their TGA curves and FTIR spectra show no uptake of water and the increase in hydroxyl vibrations was minimal. All in all, the abundantly microporous networks with short or rigid bridges showed a large uptake of water. However, the water uptake does not seem to be correlated to the carbon concentration or the hydroxyl concentration of the networks.

Hydrothermal Dissolution. The dissolution tendency of the (organo)silica materials was assessed by soaking millimetersized sample pieces, after consolidation at $300{ }^{\circ} \mathrm{C}$ for $3 \mathrm{~h}$, in aqueous solutions at $80{ }^{\circ} \mathrm{C}$ and varying $\mathrm{pH}$. The aqueous solutions contained $15 \mathrm{vol} \%$ 1,5-pentanediol to improve the solvability and solubility of organosilica molecules with significant hydrophobic character. The elemental Si concentration after soaking for $46 \mathrm{~h}$ was analyzed by ICP-OES and $\mathrm{XRF}$. ICP-OES analysis is preferred for such low concentrations due to its higher sensitivity than XRF, but ICP-OES requires atomization of $\mathrm{Si}$ and this process may be influenced by the different organic groups in the networks, possibly resulting in misinterpretation. XRF analysis does not involve atomization and therefore XRF measurements were done to seek confirmation of trends observed with ICP-OES. Results are shown in Figure 5. Note that the results indicate the degree of $\mathrm{Si}$ dissolution after soaking for $46 \mathrm{~h}$ and do not represent varying dissolution rates or equilibrium values. Since the available sample surface area was not controlled during hydrothermal treatment, care should be taken in interpreting small differences in degree of dissolution.

When comparing the organically bridged networks at $\mathrm{pH} 13$, significant concentrations of dissolved $\mathrm{Si}$ were found for BTESB > BTESM > BTESE, and only a low degree of dissolution was observed for the BTMSH- and BTESO-derived networks. This corresponds with the order in network rigidity and $\mathrm{Si}-\mathrm{O}-\mathrm{Si}$ bond strain $\mathrm{BTESB}>\mathrm{BTESM}>\mathrm{BTESE}>$ $\mathrm{BTMSH} \approx \mathrm{BTESO}$ as expected based on bridge flexibility and length and as corroborated by the ${ }^{29} \mathrm{Si}$ CP-MAS NMR (Figure 2) and FTIR (Figure 3) spectra. The same order was found for the water uptake (Figure 4), and microporosity is indeed related to the rigidity and length of the organic bridge (spacing effect). This makes it difficult to distinguish between the effects of $\mathrm{Si}-\mathrm{O}-\mathrm{Si}$ bond strain and water concentration inside the network on hydrothermal dissolution. However, comparing the extensive dissolution of PHTMS-derived material to the absent dissolution of CHTMS-derived material does confirm the importance of bond strain; both networks have a negligible water uptake and the same carbon concentration and maximum possible connectivity, but the PHTMS-derived network is expected to have significantly more bond strain due to the rigid phenyl rings. Interestingly, the high connectivity of the organically bridged networks did not prevent significant dissolution of BTESB-, BTESM-, and BTESE-derived networks. On the other hand, the MTMS-derived network was unstrained, nonporous, and hydrophobic and thus only had a low connectivity (2.9 siloxane bonds per monomer, see Table 2) to explain its dissolution. The DPDMS-derived material had a low connectivity ( 2.0 siloxane bonds per monomer) but also possible bond strain as indicated by the ${ }^{29} \mathrm{Si}$ CP-MAS NMR chemical shift, both of which may explain its extreme instability. The poorly connected PTMS- and CHTMS-derived networks (2.6 and 2.0 siloxane bonds per monomer, respectively) showed no Si dissolution, suggesting that low connectivity in turn can be compensated by hydrophobic shielding. Also, the large number of hydroxyl groups "standing by" in networks such as the one derived from CHTMS facilitates rapid bond reformation after bond breakage, thus increasing its resistance to complete disconnection despite having a low number of actual siloxane bonds. The effectiveness of hydrophobic shielding is expected to depend significantly on the positioning 
of the organic segments in the network. Note that organic shielding of siloxane bonds is not directly related to the water uptake of a material; the networks with the lowest water uptake (MTMS- and PHTMS-derived) had small and rigid organic groups with little shielding capability and showed extensive hydrothermal dissolution. In addition to shielding effects, large organic groups may provide stabilization via physical entanglement and their solvation is expected to be somewhat suppressed by the polar nature of the solvent mixture $(85 / 15$ vol \% water/1,5-pentanediol).

As for the $\mathrm{pH}$ dependence of dissolution, Si concentrations were lower at $\mathrm{pH} 1$ than at $\mathrm{pH} 7$ throughout the series of compositions. This underlines that the occurrence of hydrolysis reactions as such does not necessarily lead to net material dissolution. Hydrolysis as well as recondensation are catalyzed by acidic species, but the rate of recondensation apparently outweighed hydrolysis in the experiments discussed here. Possibly, the acidic treatment may even have improved the resistance against dissolution via network restructuring. The extensive dissolution of DPDMS-derived material at $\mathrm{pH} 13$ was only slightly lower at $\mathrm{pH} 7$ and 1 , indicating that this network was so labile that increasing catalyst concentrations did not affect the dissolution strongly. For TEOS-, BTESM-, BTESE-, BTESB-, MTMS-, and PHTMS-derived networks the dissolved Si concentration after $46 \mathrm{~h}$ was reduced by at least 2 orders of magnitude from $\mathrm{pH} 13$ to $\mathrm{pH} 7$ and $\mathrm{pH}$ 1, indicating a more kinetically limited degradation. For the BMDESE-derived network, minor dissolution was observed at $\mathrm{pH} 7$ and even less dissolution occurred at $\mathrm{pH}$ 13. A possible explanation for this unusual trend is the electron induction effect of each $\mathrm{Si}$ atom being bound to two $\mathrm{C}$ atoms instead of one or none. Organic groups are less electron-withdrawing than $\mathrm{O}$ atoms in bonds with $\mathrm{Si}$ and thus leave the $\mathrm{Si}$ atom less susceptible to nucleophilic attack (the mechanism of base-catalyzed hydrolysis, predominant at $\mathrm{pH}$ 13). Acid-catalyzed hydrolysis (increasingly dominant at lower $\mathrm{pH}$ ) involves electrophilic attack of the $\mathrm{O}$ atom and is less directly affected by electron density variations on $\mathrm{Si}$. As for the XRF results of the series, most of the ICP-OES values above the estimated XRF detection limit of about $500 \mathrm{mg} \mathrm{L}^{-1}$ were confirmed by similar $\mathrm{XRF}$ values. The ICP-OES values were not consistently lower than the XRF results, indicating no errors due to atomization effects. All in all, the results indicate a complicated balance between various stabilizing and destabilizing factors. Bond strain appears to be an important destabilizing force, while the stabilizing effect of higher connectivity is weak. No correlation is observed between hydrothermal dissolution and carbon concentration, hydroxyl concentration, or monomer mass (diffusivity after disconnection). Limited correlation is observed between hydrothermal dissolution and water uptake.

Hydrothermal stability is an important issue for application of organosilica materials in water-containing environments, e.g., as molecular separation membranes or as mesoporous supports for catalysts. Materials and devices are usually tested on structural integrity, such as maintaining mesoporous order in PMOs and maintaining separation performance in microporous membranes, and changes herein can be more subtle than the material dissolution process investigated in the present study. Nevertheless, hydrothermal dissolution is the extreme outcome of similar interactions with aqueous species. The results presented here show that extensive contact between the organosilica network and water is not problematic as long as the network flexibility and connectivity, space and shielding are properly balanced. Networks with organic groups in bridging positions are not necessarily more stable than materials with terminal organics. Even a network with an actual connectivity of two siloxane bonds per monomer can be fully resistant to dissolution (CHTMS-derived network) and almost absent hydrophilicity does not prevent it (MTMS-derived network).

\section{CONCLUSION}

The network state, water uptake, and hydrothermal dissolution of a series of organosilica materials with bridging and terminal organic groups was studied. ${ }^{29} \mathrm{Si}$ CP-MAS NMR and FTIR indicated decreasing bond strain and a slightly increasing condensation degree with increasing bridge length due to increased rotational freedom and sufficient microporosity to accommodate increasing bulkiness of the organic groups. Networks with small terminal organic groups had higher condensation degrees than the equivalent bridged networks, while bulky terminal groups sterically hindered condensation. The average number of hydroxyl groups per $\mathrm{Si}$ atom varied between 0.5 and 0.7 for the organically bridged networks, indicating significant hydrophilicity. For the networks with terminal organic groups the number of hydroxyl groups per $\mathrm{Si}$ atom varied between 0.0 and 1.0. TGA-DSC and FTIR monitoring during moisture treatments indicated a large water uptake in microporous networks with short or rigid bridges. The water uptake was not directly related to the carbon concentration or hydroxyl concentration of the networks. ICPOES and XRF analyses after hydrothermal treatment indicated that sensitivity to hydrothermal dissolution was significantly increased by bond strain. The stabilizing effect of increased connectivity was weak and no correlation was observed between hydrothermal dissolution and carbon concentration or hydroxyl concentration. Extensive contact between the organosilica network and water is not problematic as long as network flexibility and connectivity, space and shielding are properly balanced. Networks with organic groups in bridging positions are not necessarily more stable than materials with terminal organic groups.

The observed increase in hydrothermal dissolution with increasing bond strain indicates that the hydrothermal stability of a given material can be improved by relaxing the network. This can be done by further optimization of the fabrication process; the gelation and drying phases in sol-gel procedures are expected to introduce significant internal strain and more gradual transitions may be beneficial in this respect. Synthesizing materials via base catalysis instead of acid catalysis is not expected to improve hydrothermal stability, because the generally obtained higher density and connectivity may easily increase the bond strain. After synthesis, hydrothermal restructuring or catalyst post-treatments can be employed to relieve internal strain. Inducing condensation and hydrolysis in an alternating fashion may stimulate evolution of the network into a more favorable configuration via iterative reconnections, which may ultimately enable total structural relaxation. Further research on the iterative stabilization approach is currently ongoing. All in all, controlling the balance between all factors for customized material performance is an intricate challenge, but the possibilities of molecular design and network optimization reach far. 


\section{ASSOCIATED CONTENT}

\section{S Supporting Information}

The Supporting Information is available free of charge on the ACS Publications website at DOI: 10.1021/acs.langmuir.7b00971.

Overview of all deconvolutions of ${ }^{29} \mathrm{Si}$ CP-MAS NMR spectra used to obtain the condensation degrees, hydroxyl concentrations, and actual connectivities listed in Table 2. (PDF)

\section{AUTHOR INFORMATION}

\section{Corresponding Author}

*E-mail: j.e.tenelshof@utwente.nl.

\section{ORCID 1}

Johan E. ten Elshof: 0000-0001-7995-6571

\section{Notes}

The authors declare no competing financial interest.

\section{ACKNOWLEDGMENTS}

Pieter de Waard and the Wageningen NMR Centre (The Netherlands) are acknowledged for the ${ }^{29} \mathrm{Si}$ CP-MAS NMR measurements. Michiel Hamer is acknowledged for the preparation of several samples. Financial support from the Advanced Dutch Energy Materials (ADEM) program of the Dutch Ministry of Economic Affairs, Agriculture and Innovation is gratefully acknowledged.

\section{REFERENCES}

(1) Latthe, S. S.; Imai, H.; Ganesan, V.; Rao, A. V. Porous Superhydrophobic Silica Films by Sol-Gel Process. Microporous Mesoporous Mater. 2010, 130, 115-121.

(2) Purcar, V.; Stamatin, I.; Cinteza, O.; Petcu, C.; Raditoiu, V.; Ghiurea, M.; Miclaus, T.; Andronie, A. Fabrication of Hydrophobic and Antireflective Coatings Based on Hybrid Silica Films by Sol-Gel Process. Surf. Coat. Technol. 2012, 206, 4449-4454.

(3) Ma, Y.; Lee, H. R.; Okahana, K.; Kanezashi, M.; Yoshioka, T.; Tsuru, T. Preparation and Characterization of Methyl-Modified Hybrid Silica Membranes for Gas Separation. Desalin. Water Treat. 2013, 51, 5149-5154.

(4) Kanezashi, M.; Yada, K.; Yoshioka, T.; Tsuru, T. Organicinorganic Hybrid Silica Membranes with Controlled Silica Network Size: Preparation and Gas Permeation Characteristics. J. Membr. Sci. 2010, 348, 310-318.

(5) Chang, K. S.; Yoshioka, T.; Kanezashi, M.; Tsuru, T.; Tung, K.-L. A Molecular Dynamics Simulation of a Homogeneous OrganicInorganic Hybrid Silica Membrane. Chem. Commun. 2010, 46, 91409142 .

(6) Chang, K. S.; Yoshioka, T.; Kanezashi, M.; Tsuru, T.; Tung, K. L. Molecular Simulation of Micro-Structures and Gas Diffusion Behavior of Organic-Inorganic Hybrid Amorphous Silica Membranes. J. Membr. Sci. 2011, 381, 90-101.

(7) Shimoyama, T.; Yoshioka, T.; Nagasawa, H.; Kanezashi, M.; Tsuru, T. Molecular Dynamics Simulation Study on Characterization of Bis(triethoxysilyl)ethane and Bis(triethoxysilyl)ethylene Derived Silica-Based Membranes. Desalin. Water Treat. 2013, 51, 5248-5253.

(8) Castricum, H. L.; Sah, A.; Kreiter, R.; Blank, D. H. A.; Vente, J. F.; ten Elshof, J. E. Hydrothermally Stable Molecular Separation Membranes from Organically Linked Silica. J. Mater. Chem. 2008, 18, 2150-2158

(9) Castricum, H. L.; Sah, A.; Kreiter, R.; Blank, D. H. A.; Vente, J. F.; ten Elshof, J. E. Hybrid Ceramic Nanosieves: Stabilizing Nanopores with Organic Links. Chem. Commun. 2008, 1103-1105.

(10) Castricum, H. L.; Kreiter, R.; van Veen, H. M.; Blank, D. H. A.; Vente, J. F.; ten Elshof, J. E. High-Performance Hybrid Pervaporation
Membranes with Superior Hydrothermal and Acid Stability. J. Membr. Sci. 2008, 324, 111-118.

(11) Kreiter, R.; Rietkerk, M. D. A.; Castricum, H. L.; van Veen, H. M.; ten Elshof, J. E.; Vente, J. F. Stable Hybrid Silica Nanosieve Membranes for the Dehydration of Lower Alcohols. ChemSusChem 2009, 2, 158-160.

(12) van Veen, H. M.; Rietkerk, M. D. A.; Shanahan, D. P.; van Tuel, M. M. A.; Kreiter, R.; Castricum, H. L.; ten Elshof, J. E.; Vente, J. F. Pushing Membrane Stability Boundaries with $\mathrm{HybSi}{ }^{\circledR}$ Pervaporation Membranes. J. Membr. Sci. 2011, 380, 124-131.

(13) Kanezashi, M.; Yada, K.; Yoshioka, T.; Tsuru, T. Design of Silica Networks for Development of Highly Permeable Hydrogen Separation Membranes with Hydrothermal Stability. J. Am. Chem. Soc. 2009, 131, 414-415.

(14) Xu, R.; Wang, J.; Kanezashi, M.; Yoshioka, T.; Tsuru, T. Development of Robust Organosilica Membranes for Reverse Osmosis. Langmuir 2011, 27, 13996-13999.

(15) Xu, R.; Wang, J.; Kanezashi, M.; Yoshioka, T.; Tsuru, T. Reverse Osmosis Performance of Organosilica Membranes and Comparison with the Pervaporation and Gas Permeation Properties. AIChE J. 2013 59, 1298-1307.

(16) Castricum, H. L.; Paradis, G. G.; Mittelmeijer-Hazeleger, M. C.; Bras, W.; Eeckhaut, G.; Vente, J. F.; Rothenberg, G.; ten Elshof, J. E. Tuning the Nanopore Structure and Separation Behavior of Hybrid Organosilica Membranes. Microporous Mesoporous Mater. 2014, 185, 224-234.

(17) Song, H.; Zhao, S.; Chen, J.; Qi, H. Hydrothermally Stable ZrDoped Organosilica Membranes for $\mathrm{H} 2 / \mathrm{CO} 2$ Separation. Microporous Mesoporous Mater. 2016, 224, 277-284.

(18) Song, H.; Zhao, S.; Lei, J.; Wang, C.; Qi, H. Pd-Doped Organosilica Membrane with Enhanced Gas Permeability and Hydrothermal Stability for Gas Separation. J. Mater. Sci. 2016, 51, 6275-6286.

(19) Melde, B. J.; Holland, B. T.; Blanford, C. F.; Stein, A. Mesoporous Sieves with Unified Hybrid Inorganic/organic Frameworks. Chem. Mater. 1999, 11, 3302-3308.

(20) Burleigh, M. C.; Markowitz, M. A.; Jayasundera, S.; Spector, M. S.; Thomas, C. W.; Gaber, B. P. Mechanical and Hydrothermal Stabilities of Aged Periodic Mesoporous Organosilicas. J. Phys. Chem. B 2003, 107, 12628-12634.

(21) Yang, Q.; Li, Y.; Zhang, L.; Yang, J.; Liu, J.; Li, C. Hydrothermal Stability and Catalytic Activity of Aluminum-Containing Mesoporous Ethane-Silicas. J. Phys. Chem. B 2004, 108, 7934-7937.

(22) Guo, W.; Li, X.; Zhao, X. S. Understanding the Hydrothermal Stability of Large-Pore Periodic Mesoporous Organosilicas and Pure Silicas. Microporous Mesoporous Mater. 2006, 93, 285-293.

(23) Goethals, F.; Vercaemst, C.; Cloet, V.; Hoste, S.; van der Voort, P.; van Driessche, I. Comparative Study of Ethylene- and EthenyleneBridged Periodic Mesoporous Organosilicas. Microporous Mesoporous Mater. 2010, 131, 68-74.

(24) Esquivel, D.; Jiménez-Sanchidrián, C.; Romero-Salguero, F. J. Comparison of the Thermal and Hydrothermal Stabilities of Ethylene, Ethylidene, Phenylene and Biphenylene Bridged Periodic Mesoporous Organosilicas. Mater. Lett. 2011, 65, 1460-1462.

(25) Smeulders, G.; Meynen, V.; Silvestre-Albero, A.; Houthoofd, K.; Mertens, M.; Silvestre-Albero, J.; Martens, J. A.; Cool, P. The Impact of Framework Organic Functional Groups on the Hydrophobicity and Overall Stability of Mesoporous Silica Materials. Mater. Chem. Phys. 2012, 132, 1077-1088.

(26) Xia, Y.; Wang, W.; Mokaya, R. Bifunctional Hybrid Mesoporous Organoaluminosilicates with Molecularly Ordered Ethylene Groups. J. Am. Chem. Soc. 2005, 127, 790-798.

(27) Inagaki, S.; Guan, S.; Ohsuna, T.; Terasaki, O. An Ordered Mesoporous Organosilica Hybrid Material with a Crystal-like Wall Structure. Nature 2002, 416, 304-307.

(28) Cho, E. B.; Char, K. Macromolecular Templating Approach for the Synthesis of Hydrothermally Stable Mesoporous Organosilicas with High Periodicity and Thick Framework Walls. Chem. Mater. 2004, 16, 270-275. 
(29) Wahab, M. A.; Chaobin, H. Hydrothermally Stable Periodic Mesoporous Ethane-Silica and Bimodal Mesoporous Nanostructures. J. Nanosci. Nanotechnol. 2011, 11, 8481-8487.

(30) Xia, Y.; Mokaya, R. High Surface Area Ethylene-Bridged Mesoporous and Supermicroporous Organosilica Spheres. Microporous Mesoporous Mater. 2005, 86, 231-242.

(31) López, M. I.; Esquivel, D.; Jiménez-Sanchidrián, C.; van der Voort, P.; Romero-Salguero, F. J. Vulcanized Ethene-PMO: A New Strategy to Create Ultrastable Support Materials and Adsorbents. J. Phys. Chem. C 2014, 118, 17862-17869.

(32) Dral, A. P.; Tempelman, K.; Kappert, E. J.; Winnubst, L.; Benes, N. E.; ten Elshof, J. E. Long-Term Flexibility-Based Structural Evolution and Condensation in Microporous Organosilica Membranes for Gas Separation. J. Mater. Chem. A 2017, 5, 1268-1281.

(33) López Pérez, L.; van Eck, E. R. H.; Melián-Cabrera, I. On the Hydrothermal Stability of MCM-41. Evidence of Capillary TensionInduced Effects. Microporous Mesoporous Mater. 2016, 220, 88-98.

(34) Sayari, A.; Liu, P.; Kruk, M.; Jaroniec, M. Characterization of Large-Pore MCM-41 Molecular Sieves Obtained via Hydrothermal Restructuring. Chem. Mater. 1997, 9, 2499-2506.

(35) Kruk, M.; Jaroniec, M.; Sayari, A. Influence of Hydrothermal Restructuring Conditions on Structural Properties of Mesoporous Molecular Sieves. Microporous Mesoporous Mater. 1999, 27, 217-229.

(36) Yoshida, K.; Hirano, Y.; Fujii, H.; Tsuru, T.; Asaeda, M. Hydrothermal Stability and Performance of Silica-Zirconia Membranes for Hydrogen Separation in Hydrothermal Conditions. J. Chem. Eng. Jpn. 2001, 34, 523-530.

(37) Lin, H.-P.; Mou, C.-Y. Salt Effect in Post-Synthesis Hydrothermal Treatment of MCM-41. Microporous Mesoporous Mater. 2002, $55,69-80$.

(38) Lei, J. H.; Liu, D.; Guo, L. P.; Yan, X. M.; Tong, H. Fabrication and Characterization of Hexagonal Mesoporous Silica Monolith via Post-Synthesized Hydrothermal Process. J. Sol-Gel Sci. Technol. 2006, 39, 169-174.

(39) Lin, H. P.; Mou, C. Y.; Liu, S. B. Ammonia Hydrothermal Treatment on Mesoporous Silica Structure Synthesized from Acidic Route. Chem. Lett. 1999, 28, 1341-1342.

(40) Lin, H. P.; Mou, C. Y.; Liu, S. Bin. Formation of Mesoporous Silica Nanotubes. Adv. Mater. 2000, 12, 103-106.

(41) Melnyk, I. V.; Zub, Y. L.; Véron, E.; Massiot, D.; Cacciaguerra, T.; Alonso, B. Spray-Dried Mesoporous Silica Microspheres with Adjustable Textures and Pore Surfaces Homogenously Covered by Accessible Thiol Functions. J. Mater. Chem. 2008, 18, 1368-1382.

(42) Wang, J.; Gong, G.; Kanezashi, M.; Yoshioka, T.; Ito, K.; Tsuru, T. Pore-Size Tuning of Highly Selective Organic-Inorganic Hybrid Silica Membranes by Solid-Phase Post-Treatment at Low Temperature. Chem. Lett. 2012, 41, 1663-1665.

(43) Wang, J.; Gong, G.; Kanezashi, M.; Yoshioka, T.; Ito, K.; Tsuru, T. Pervaporation Performance and Characterization of Organosilica Membranes with a Tuned Pore Size by Solid-Phase $\mathrm{HCl}$ PostTreatment. J. Membr. Sci. 2013, 441, 120-128.

(44) Gong, G.; Nagasawa, H.; Kanezashi, M.; Tsuru, T. Tailoring the Separation Behavior of Polymer-Supported Organosilica LayeredHybrid Membranes via Facile Post-Treatment Using $\mathrm{HCl}$ and NH3 Vapors. ACS Appl. Mater. Interfaces 2016, 8, 11060-11069.

(45) Wang, W.; Grozea, D.; Kohli, S.; Perovic, D. D.; Ozin, G. A. Water Repellent Periodic Mesoporous Organosilicas. ACS Nano 2011, 5, 1267-1275.

(46) Cerveau, G.; Corriu, R. J. P.; Lepeytre, C.; Mutin, P. H. Influence of the Nature of the Organic Precursor on the Textural and Chemical Properties of Silsesquioxane Materials. J. Mater. Chem. 1998, 8, 2707-2713.

(47) Cerveau, G.; Corriu, R. J. P.; Dabosi, J.; Fischmeister-Lepeytre, C.; Combarieu, R. Characterization of the Surface Organization of Nanostructured Hybrid Organic-Inorganic Materials by Time-of-Flight Secondary Ion Mass Spectrometry. Rapid Commun. Mass Spectrom. 1999, 13, 2183-2190.
(48) ten Elshof, J. E.; Dral, A. P. Structure-property Tuning in Hydrothermally Stable Sol-gel-Processed Hybrid Organosilica Molecular Sieving Membranes. J. Sol-Gel Sci. Technol. 2016, 79, 279-294.

(49) Wragg, D. S.; Morris, R. E.; Burton, A. W. Pure Silica ZeoliteType Frameworks: A Structural Analysis. Chem. Mater. 2008, 20, $1561-1570$.

(50) Mohanty, P.; Kokoszka, B.; Liu, C.; Weinberger, M.; Mandal, M.; Stagno, V.; Fei, Y.; Landskron, K. Large-Pore Periodic Mesoporous Silicas with Crystalline Channel Walls and Exceptional Hydrothermal Stability Synthesized by a General High-Pressure Nanocasting Route. Microporous Mesoporous Mater. 2012, 152, 214218.

(51) Li, D.; Han, Y.; Song, J.; Zhao, L.; Xu, X.; Di, Y.; Xiao, F.-S. High-Temperature Synthesis of Stable Ordered Mesoporous Silica Materials by Using Fluorocarbon-Hydrocarbon Surfactant Mixtures. Chem. - Eur. J. 2004, 10, 5911-5922.

(52) Viitala, R.; Jokinen, M.; Tuusa, S.; Rosenholm, J. B.; Jalonen, H. Adjustably Bioresorbable Sol-Gel Derived SiO2Matrices for Release of Large Biologically Active Molecules. J. Sol-Gel Sci. Technol. 2005, 36, $147-156$.

(53) Castricum, H. L.; Paradis, G. G.; Mittelmeijer-Hazeleger, M. C.; Kreiter, R.; Vente, J. F.; ten Elshof, J. E. Tailoring the Separation Behavior of Hybrid Organosilica Membranes by Adjusting the Structure of the Organic Bridging Group. Adv. Funct. Mater. 2011, 21, 2319-2329.

(54) Bergna, H. E., Roberts, W. O., Eds.; Colloidal Silica: Fundamentals and Applications; CRC Press, Taylor \& Francis Group: Boca Raton, FL, 2005; p 69.

(55) Launer, P. J. Infrared Analysis of Organosilicon Compounds: Spectra-Structure Correlations. Silicone Compounds Register and Review 1987, 100-103.

(56) Socrates, G. Infrared Characteristic Group Frequencies: Tables and Charts, 2nd ed.; Wiley: Chichester, U.K., 1994.

(57) Smith, A. L., Ed.; The Analytical Chemistry of Silicones; Wiley: New York, 1991; pp 373-374.

(58) Liepins, E.; Zicmane, I.; Lukevics, E. A Multinuclear NMR Spectroscopy Study of Alkoxysilanes. J. Organomet. Chem. 1986, 306, $167-182$.

(59) Oviatt, H. W.; Shea, K. J.; Small, J. H. Alkylene-Bridged Silsesquioxane Sol-Gel Synthesis and Xerogel Characterization. Molecular Requirements for Porosity. Chem. Mater. 1993, 5, 943-950.

(60) Glaser, R. H.; Wilkes, G. L.; Bronnimann, C. E. Solid-State 29Si NMR of TEOS-Based Multifunctional Sol-Gel Materials. J. Non-Cryst. Solids 1989, 113, 73-87.

(61) Handke, B.; Jastrzebski, W.; Mozgawa, W.; Kowalewska, A. Structural Studies of Crystalline Octamethylsilsesquioxane (CH3)8Si8O12. J. Mol. Struct. 2008, 887, 159-164.

(62) Iwamura, T.; Adachi, K.; Chujo, Y. Simple and Rapid EcoFriendly Synthesis of Cubic Octamethylsilsesquioxane Using Microwave Irradiation. Chem. Lett. 2010, 39, 354-355.

(63) Davis, K. M.; Tomozawa, M. An Infrared Spectroscopic Study of Water-Related Species in Silica Glasses. J. Non-Cryst. Solids 1996, 201, 177-198. 